\title{
The Research Journey: Through the Lens of the Adult Learner
}

\author{
Dr Angela Wright \\ Department of Organisation \& Professional Development \\ School of Business, CIT, Bishopstown, Cork, Ireland \\ E-mail: angela.wright@cit.ie
}

Received: Dec. 8, 2015 Accepted: Jan. 14, 2016 Published: February 1, 2016

doi:10.5296/jse.v6i1.8692ＵRL: http://dx.doi.org/10.5296/jse.v6i1.8692

\begin{abstract}
This research provides an opportunity to reflect, evaluate and to implement better procedures for practice, specifically, the research supervision of post graduate students at the taught Masters Level. In this context, empirical data were gathered from recently graduated 'taught masters' students in the business arena in an Irish Third Level Institution. The main objective was to understand their specific research and learning needs better. This current research is novel, as an examination of the academic literature in relation to this area is scant. It is envisaged that this research will provide a 'voice' for the students in this field. A quantitative approach was applied and data were gathered from 62 adult graduates.

The main finding of this study concerns the alignment of the programme as a whole, where it has become apparent and recommended that a taught module on the programme, 'research methods'(a mandatory module) will need to be delivered just prior to the commencement of the research thesis module that this research paper appraises. Currently, it is delivered over a year before commencement of the research thesis proper to the students. Overall, the findings are positive and are discussed in detail in this research.

The main aim of this evaluation of current practices is to establish where improvements can be made as a direct result of the recommendations from the recent graduates in this study. These recommendations will be considered, and relevant resultant changes will be made to improve future practice. It is envisaged that the findings of this research will better inform the author, the Department, and the Faculty of Business \& Humanities for future programmatic reviews. The objective is that more effective methods will be established for future students to achieve their own learning and research objectives more effectively.
\end{abstract}


Keywords: Research Supervision, Supervisory Styles, Student Challenges, Masters Level, Instructor Evaluation, Reflection. 


\section{Introduction}

Teaching matters as much as research matters

(McAleese et al., 2013).

Quality teaching and learning has broad horizons, taking place in a research-rich environment, where the subject matter is driven by the latest knowledge and research, delivered in a way which encourages students to develop academic literacy and both subject specific and generic skills which they can apply immediately in the real world, especially in the labour market (McAleese et al., 2013). The intention of this research is specifically to broaden the author's own personal teaching horizons particularly, and the current research supervision practices and approaches in place, with a view to gaining insights and knowledge directly from the student cohort so as to improve the practice of same.

Evaluation studies are fundamentally about asking questions, and then designing ways to try to find useful answers. Studies may concern materials, projects, courses, methods, packages, or systems; in fact, anything that can be asked about in a detailed, structured fashion (Moon, 2001; Harvey, 1998). The students who cooperated in this evaluation are adult learners who take their educational studies on a part-time base, while working full time. These adult learners are over twenty three years, employed and assuming multiple adult roles. Adult learners and how they learn (andragogy) is of great interest to the author, having worked constantly with such learners for eleven years. From an educator's perspective, the adult learner is a challenge which requires a full understanding of andragogy. This research provides a timely opportunity to examine the research practices applied by the author. For the purpose of this research paper, research supervision of the part-time Masters of Business Studies (MBS Taught) will be reviewed.

Research supervision places one at the epicentre of new and exciting empirical data, while equally placing an immense challenge and responsibility on one's shoulders - namely, the successful graduation of students under one's supervisory care. In terms of staying informed, academics who constantly engage in academic research are most useful to research students, and are more likely to enable student achievement (Brew \& Boud, 1995). Whether examined from the "research angle, or the teaching angle, research learning provides the link which is capable of adding new vitality to the debate" (1995:272). In line with Brew \& Boud, this researcher believes that it is vital that all researchers engage in their own ongoing personal research journey. In this current research, the students were asked if they felt that their supervisor was adequately informed, hence, enabling confidence in their own research journey. This research addresses a dearth in the academic literature, specifically in relation to adult learner supervision, providing a 'voice' for the students and an opportunity to provide valuable information that can be applied in practice and built upon.

\subsection{Research Thesis [taught]}

The taught research supervision begins each year on February 1, and continues as long as possible within the obligatory time-frame. With supervision, there is no 'end of term' as such for the author, and students are advised continually until the hand-up date at the end of the 
first week of September. The time span is relatively short, given that many students are very ambitious with their research inputs and outputs. Again, the adult learners are ambitious (Ramsden, 1992), and see the final thesis as a vehicle for their future careers. The term begins with a general class for a duration of two weeks, and, from here, it breaks out into individual meetings with students. Given the numbers, the author sees each student once a fortnight, $(11 / 12$ students are seen each week). This takes about five hours per week to complete. In the meantime, if students are struggling, they are encouraged to make an individual separate appointment outside of the allocated time. The author has the benefit of also teaching the students for the research methods module. The content of this module comprises of teaching research methods, and developing a research proposal for the thesis proper that begins on February 1. This subject is taken in the first year of the programme, however, and the thesis is not taken until the last semester of the last year. So, for example, students commencing a taught MBS in September 2015, take the research methods module in the first term, but they will not begin their thesis proper until February 2017.

\section{Aims \& Objectives of this Research}

The main aim of this research is to examine in detail the current supervisory practices and processes applied for the thesis element of the 'taught masters' specifically.

The main objective of this research will be to inform practice, and to move forward in a supervisory capacity with more appropriate informed thinking. Another objective is to develop new processes to facilitate future supervisory student engagement. This will emerge as a direct result of the empirical findings of this research.

\section{Methodology}

For the purposes of this research study, it was considered appropriate to apply a positivistic research methodology. A quantitative research survey instrument was devised based on surveys and suggestion on educational research on Survey Monkey. The majority of these suggested questions were used, but other questions were included to capture all of the necessary data, and to include questions on constructive alignment, (Entwistle, 2009), for example. Quantitative measurements and hard facts may be of more use in demonstrating concrete achievement to the researcher (Harvey, 1998). The survey was completely confidential as it was deemed that it was necessary to make contributions confidential and anonymous to access negative feedback from students (Harvey, 1998). This allowed them the freedom and confidence to make a relevant and genuine contribution to the research.

One hundred and forty-nine students have been supervised by the author to date. This consists of the entire population, but it was considered more reliable to sample students who completed their thesis in the last three years, including 2014, as it was considered that, outside of this timeframe, it would have been too long ago in the memory of the student to give an accurate opinion of the supervision received, and data could be biased and not valid. Questionnaires, like many evaluation methods, occur after the event, so participants may forget important issues (Harvey, 1998). Hence, the sample size was as follows: 
Table 1.

\begin{tabular}{|l|l|}
\hline YEAR & TOTAL SUPERVISED \\
\hline 2012 & 26 \\
\hline 2013 & 17 \\
\hline 2014 & 19 \\
\hline TOTAL & $\mathbf{6 2}$ \\
\hline
\end{tabular}

A sample of 62 students was considered an appropriate sample size. Prior to sending out the survey, the questionnaire was tested to eliminate any errors and cleansed prior to surveying the sample proper. The pilot test was conducted with a current $\mathrm{PhD}$ student who had completed a taught masters with the author in the past three years. Colleagues were also consulted, and recommendations from them were incorporated into the revised survey. When the survey was ready, an email was sent to the 62 students with the survey link attached with a request to complete same in the interest of improving practice. Four of the emails bounced (the emails on file were work emails), implying that the students had moved from their work and relevant email to another position. Therefore, the working sample was reduced to 58 . The response rate was good with 40 students of the relevant 58 taking the survey - a response rate of $68.96-70 \%$

\section{Literature}

\subsection{The Adult Learner}

As many older adults now return to education to up-skill and enhance career progression, a new "interest in older learners has grown considerably into the motivation for same, anecdotally referred to as on how to teach 'old dogs new tricks'," , (Gegenfurtner, \& Vauras, 2012:46). Adult learners bring varying standpoints to education, in terms of emotion, motivation, and financial resource, when compared to students entering higher education through the CAO from Leaving Certificate. Students learn differently in varying situations (Ramsden, 1992), and this is to the fore with adult learners. Connotation varies greatly with each student but especially with the adult learner (Ramsden, 1992; Enthwistle, 2009).

Adult learners are defined either based on their age, cognitive maturity, or as a non-traditional learner (Yap, 2009). Penn State commission (2012) offer a similar description and outline that an adult learner is 24 years or older; or is a veteran of the armed services; or an active duty service member; or is returning to school after four or more years of employment, homemaking, or other activity; or assumes multiple adult roles such as parent, spouse/partner, employee, and student (www.outreach.psu.edu/commission). Adult learners have their own view of the world, a notion of what is needed to survive and succeed, and their own personal view of success (Yap, 2009). Many adult learners also bring experiential learning to further education (Rogers, 1969) and embrace self-direction (Yap, 2009).

\subsubsection{The Adult Learner and Motivation}

Reasons and purpose for learning are varied (Yap, 2009), but, for many adults, professional advancement and stimulation are key factors. Motivation to learn is associated with meaningful cognitive engagement with the training content. Maslow's hierarchy of needs 
(1943), (a pyramid consisting of 5 levels of motivation) explains motivation, with the adult learner fitting into the higher level-'self-actualisation'. Alderfer expanded Maslow's work and introduced the ERG theory; namely existence, relatedness and growth. It is important to know where an adult is in the life cycle; for example, those in the relatedness category are more concerned with learning, and those in the existence category are more economically comfortable (Yap, 2009). Social interaction is important, and the expectation of contact with peers seems to be emotionally meaningful, especially for adults, (Gegenfurtner \& Vauras, 2012).

\section{Supervisory Styles}

Research supervision is the most advanced level of teaching (Zhao, 2001) and is a process of fostering and enhancing learning, research and communication at the highest level in the educational system, (Laske \& Zuber-Skerritt, 1996). The student and the supervisory relationship are inextricably linked during the thesis process (Armstrong, 2004), and the relationship process can also change throughout the period. This is mainly due to the style of the supervision (Armstrong, 2004). Cullen (2009) believes that the relationships are intricate and advice is needed; however, the advisory literature available to academics is scant, and hence, many supervisors have a dearth of literature from which to draw. Cullen advises that the academic community is endeavouring to bridge that gap.

The roles and functions of research supervision are multiple and vary in the perception of its different stakeholders. In the view of students, the ideal supervision helps them to achieve a scientific, professional or personal goal, and to learn about research and how to conduct research against the quality standards of the system (Zhao, 2001).

\subsection{Approaches to Research Supervision}

Teaching and learning in higher education is a shared process, with responsibilities on both student and teacher to contribute to their success. Within this shared process, higher education must engage students in questioning their preconceived ideas and their models of how the world works, so that they can reach a higher level of understanding (McAleese, 2013). Student and lecturer expectations can often be mismatched, however, posing anxiety for the learner and supervisor alike (Sorcinelli et al., 2007).

In terms of research supervision, various approaches exist such as (Gatfield, 2005; Lee, 2007), that offer four approaches to the supervision. Gatfield (2005), for example, outlined a model using four main supervisory styles. The model proposed utilising 'support' and 'structure'. The four elements proposed by Gatfield are as follows: Pastoral Care-low structure and high support; Contractual Style — high structure and high support, Laissez Faire-low structure low support; and Directorial Style-high structure and low support (researchsuper.chelt.anu.edu.au). Lee also proposes four models of supervision; Functional, Critical Thinking, Enculturation \& Mentoring, and discusses links with Brew's research.

A Functional Model (Lee, 2007) is when the supervisor has a structured approach to the supervisory process and it is suggested to use a table to log details whereby a process is adhered 
to (Lee, 2007). Zhao (2001) also advocates a practice research plan and encourages good planning over 'ad hoc' processes.

Emancipation - A Mentoring Process and Relationship Building is a method when the mentor is a coach who provides all the support but allows the student space to breath. Problems may arise with responsibility - who should be responsible? Supervisors who adopts a mentoring approach need to be very careful that they do not become noxious to the student (Lee, 2007).

\section{Main Findings \& Discussion}

Students are not fearful of voicing their opinion on delivery of course content (Lewis, 2010). Students exercise some control over the quality of their learning by "evaluating their teachers' performance" (Sorcinelli, et al., 2006: 2), and the results of the empirical data provide a voice for the students in this context.

The findings of this research are analysed individually. There is only one instance of a combined result, and this is under the theme of Motivation. The rest of the results are interpreted 'as is' - high and low percentages of findings. The findings are also outlined under two main themes:

Theme 1 Instruction, covering teaching, explanation, knowledge, organisation, methods, speed of delivery, student progress, alignment.

Theme 2 Motivation, covering student motivation, student understating of assessment.

In terms of the supervision of the students, given the limitation on the time for supervision, it is important that the supervision is structured from the outset, in order to achieve the outcomes of the module. The student is given a specific date/time and duration for each meeting. Attendance, duration and discussions are documented, together with suggestions, directions, and areas to be investigated before the next meeting. Actions are generated that will be referred to at the next supervisor/ student meeting.

As a supervisor, the author embraces a dual approach to supervision. At the beginning of the early research stage, a more functional and instructional approach is implemented. Once the student has grasped some of the research techniques, it is much more beneficial if the supervisor becomes a mentor to them. This provides space for the research student to find 'his/her own way' through the research process, and to discover in an independent and non-directed way what one's own personal research journey can achieve. With the majority, this is what the author aims to accomplish and, in most cases, it is successful, but there are some cases where the students need a more 'hands on' direction, and struggle in a serious way with self-directed learning. In some cases, a combination of styles dependent on the student ability and situation are used. No two situations are the same and, as a supervisor, it is difficult to be consistent. While one does gain extensive supervisory experience over the years, it is still necessary to adopt and continually change to differing circumstances and different student personalities. 


\section{Theme 1 Instruction}

Empirical findings from the student feedback survey outline that, in terms of satisfaction in relation to instruction and teaching by the author, $65 \%$ of students stated that they were "quite satisfied", $20 \%$ were "somewhat satisfied", while on the negative side, $5 \%$, "were extremely dissatisfied". Comments and suggestions such as "better tutor to pupil ratio" were offered which is not surprising, as the author is tasked with the full supervision of this class on an annual basis. What was interesting was that four of the 40 respondents suggested that the research methodology module should not be taught at the beginning of the course as it currently stands, and that it should be moved and taught just prior to the thesis proper. Comments generated are as follows:

*The research method module should be part of the 2 nd year 1 st semester not in year $1-1^{\text {st }}$ semester. *Chapter 3, research method, could be started earlier in the course to assist the practical application for a better understanding of the methods. Or, maybe it could be presented as a stand-alone module. *The research methods are a fundamental part of the thesis and are important to students who may wish to advance from the masters.

*Could the Semester 1 module on research be done in Semester 3, i.e., just before the thesis proper is attempted so that the material is fresh in our minds?

As can be seen, $10 \%$ of participants offered similar comments in relation to the research methodology module. This very same debate has taken place at the course board meeting level. As discussed earlier, a time span of one full year exists between writing the research proposal and writing the thesis proper. This is an area that should be addressed and reviewed. The author believes that the programme as a whole would align better if the research methods and the assignment for same (research proposal) were completed in December, and that the students would continue on and start the thesis in February (semester 2). Constructive alignment maximises the conditions for quality learning as it ensures that programmes are aligned throughout the entire process (Donnelly \& Fitzmaurice, 2005). Constructive alignment is important for quality learning, but it is vital that teaching methods, the correct Learning Outcomes (LO), how student's construct the correct meaning, and the assessments, all relate to and support each other (Biggs, 2003; 1999). In aligned teaching, there is maximum consistency throughout the system. Objectives are clearly outlined, the teaching method should be one that will realise those objectives-students do things that the objectives nominate, and the assessment task addresses the objectives. The instructor should be able to test if the students have learned what the objectives state, and if there is consistency, "constructive alignment", (Biggs, 1999:64). Interestingly, however, when asked in the research survey if the students believed that the module was properly aligned, 55\% stated that module aims, teaching and assessment were "extremely well aligned", $27.5 \%$ "quite well", 10\% "moderately well", 5\%"slightly well", and 2.5\% (1 student) "not at all well”.

Realistically, it would be important for the instructor to examine the alignment of the programme again, as $17.5 \%$ of contributors were not completely satisfied with the alignment. This in part, is due to the research methods module being delivered a whole year before the 
research thesis. One student suggested that he would have "benefited from doing at least some of the research before doing literature review, as Chapter 2, became a millstone around their neck", but in practice, this suggestion could never be implemented, as the literature will always have to be completed first. This, however, does alert the author to the misunderstanding that exists in relation to the importance of the literature review.

Brew and Boud (1995) outline the importance of instructor knowledge. In the context of this research study and, specifically, knowledge of the instructor, $70 \%$ of the respondents believe that the instructor was "extremely knowledgeable", while 1 participant stated that the instructor was "slightly knowledgeable", with 0 results for "not at all knowledgeable". Comments from participants in this section reflect Lee (2007):

*A template document for guidelines on format and layout of the thesis would be helpful.

*More time should be spent on the various methods of analysing data from qualitative research.

The first comment here is surprising as specific instructions for format and layout are certainly given to all students. This comment makes the author realise that even though one believes that one is connecting with the students - you will always miss one. Careful attention must be paid in the future to reach all students at all times.

When asked how clearly the material was explained by the instructor, $60 \%$ of the students stated "quite clearly", 30\% "moderately", however, 10\% stated that they were slightly confused. Comments in relation to this are as follows:

*The difficulty arose not with the material but in the confidence in what to do next, so it wasn't going to be a waste of two weeks. A bit like lost in the wilderness and you meet someone after three days; ask for directions to the main road and after the conversation you are none the wiser. Hence, more anxious days searching for a glimpse of the main road.

*I did get confused at different times but this was also due to this being my first experience of thesis writing.

Again the author is available to all students each week, so maybe if more structured note taking were made compulsory for each student at each meeting, it may elevate the 'wilderness and anxiousness' problem as outlined above.

Time management was a problem for the students with many struggling to collate their empirical data. One student outlined that "chapter 4, the findings chapter, was extremely time consuming, never mind chapter 5, (analysis) which requires at least four weeks from start to finish".

It may be beneficial to have additional classes on time management and planning at the beginning of the semester to emphasis this issue. Students are told how much time and effort is needed each week and how to go about their work in a timely manner, but, year on year, time management does crop up as a major issue. The only way of realising this is by going through the actual research process, but, unfortunately, students realise too late that they are 
in trouble. In the past, the author has had students from past years come in to talk to the thesis class and to go through their own personal experiences. It may be necessary to have another of these visits mid-semester to remind students again about time management; ideally, one graduate visit at the beginning and another mid-way through the semester.

There were no major issues in relation to speed of delivery; $75 \%$ of respondents stated that the module was delivered at "about the right speed". One participant stated that the speed was "too slow"; while $22.5 \%$ (9) stated that it was "somewhat too quickly". Comments were as follows:

*Not enough methodology theory presented prior to research being undertaken.

*I would prefer to see phase one taken from term one into two.

*Hard for a supervisor to pace this based on the general class pace as everyone was working at different speeds.

Again, what is interesting here from the primary data is the fact that the research methodology module is mentioned again as being delivered in the wrong place in the programme; this would certainly indicate that there is a real need to re-look at the alignment of the overall MBS programme, specifically where the research methodology and the writing of the research proposal arise within the programme context. This will be a priority for programmatic review in 2015.

Ramsden (2003) suggests that it is important for the student to have confidence in the instructor, and this can be enhanced by how well organised and prepared the instructor is. The findings from the empirical data reveal that, in terms of organisation of the module by the supervisor, $47.5 \%$ of participants stated "extremely well", $33.5 \%$ stated "quite well organised' and on the negative side, $2.5 \%$ ( 1 person) stated "not at all well organised". There was one interesting comment as follows:

*A few lectures on how to prepare a roadmap prior to starting the research project would be very helpful.

Again reflecting the writings of Lee (2007), an opportunity for improvement exists here in terms of delivery. Is it justified to suggest that roadmaps should be provided for this module?

When asked about the feedback that they received directly from the supervisor, $50 \%$ stated that the feedback was "extremely valuable", while on the negative side, $22.5 \%$ stated that it was "adequate". Feedback to students has many benefits (Boud \& Falchikov), but, unfortunately, Brown (2007) outlines that students tend not to use feedback constructively. Again comments refer back to the previous question in terms of fixed deadlines and roadmaps (Lee), where the following comment was offered:

*If there were cast iron deadlines for each chapter to be submitted e.g., Literature review-week 4, methodology week 6, etc., and was corrected with suggestions \& returned to the budding researcher it would be a terrific help. 
This is something that can certainly be looked at for the future. In the past, strict deadlines were implemented, but this did not work either with students working at different paces and missing deadlines. This is a delicate area and difficult to find a solution. Mirroring Cullen (2009), there is a void in the academic literature on research supervision with scant aids available to the supervisor.

\section{Theme 2 Motivation}

When it came to motivation, and how motivated the students were by the lecturer's input, $50 \%$ stated that they were "extremely motivated", 30\% "quite well", $12.5 \%$ "moderately well", $2.5 \%$ slightly well", and 5\% (2 students) "not at all well". Combining the top two results $(50+30)$ reveal that $80 \%$ of the contributors are well motivated. The thesis is worth 20 credits for this programme, - therefore, it would be interesting to look at how best to motivate the remaining $20 \%$ to their optimum. The comment below was offered and is an interesting one to take on board reflecting (Yap, 2009), where adult learners need additional motivators.

*A dedicated project supervisor (external maybe from industry) with no more than 4 students, who would act as the student's research sage for the duration of research.

This suggestion is an excellent one, as it could further motivate and align with what the students envisage that their outcomes would be from the finished research. It could also allow for the students to aspire to the industry standards in relation to their specific research.

When it comes to assessments, students are less concerned with teaching activities and much more concerned with how we assess (Race, 1993). Assessments and accountability, new technologies, diverse students, institutions striving to achieve 'the next level', all have an impact on, and place pressures on both Teaching and Learning (Dewar, 2010), and when it came to the feedback in this research on how the final thesis was graded and how well the students understood this process, 52,5\% stated "extremely clearly", 27.5\% stated "quite clearly", $12.5 \%$ "moderately clearly", $5 \%$ "slightly clearly", and 2.5\% (1 student) "not at all clearly". One comment was offered as follows:

*It was very well explained on a few occasions.

Race (1993) believes that, for the students, it is all about the 'result'; in this case, when it came to the actual fairness of the actual grade received for their final thesis work, $55 \%$ of those surveyed believed that is was "extremely fair", 37.5\% "quite fair", 5\% "moderately fair", and 2.5\% "slightly fair". Nobody ticked the "not at all fairly" box in this case. One comment was offered as follows:

*The final grading could be broken down into the sections and grading marks shown per section. That way you could see where the marks were gained/lost.

Combining the top two results, (92.5\%) reveals a very positive result, and agrees with Race, (1993), that our biggest contribution to our students' learning is directly associated with the quality of their assessment. In the context of this research, the students are given a very detailed breakdown of the grading system for their thesis, but, reflecting Harvey (1998), one 
has to be mindful that this issue was raised by the students even though this was available to them.

\section{Recommendations}

It is most beneficial to put teaching "under the spotlight", (Biggs, 1999:73), thereby, providing useful reflection. Many problems arise for educators when delivering programmes; many do not understand alignment and many instructors did not write the LOS initially (Ullah et al., 2011). The best teaching encourages students to be aware of and to draw on the research not only of the teacher, but also of fellow academics within and beyond the university or college, including internationally. In this era of increasingly rapid globalisation, the teaching and learning experience for all students must be globally connected, enabling students to develop an understanding of how their subject is viewed and pursued in different parts of the world (McAleese et al., 2013). Harvey (1998) believes that we evaluate to learn. Improving practice has encouraged the researcher to evaluate and reflect on the current supervisory process in place. This has ensured reflection and ways to learn from mistakes and improve for the future. It is paramount to understand teaching so as to improve student learning (Ramsden, 2003).

The findings of the student survey mirror the views of Harvey (1998), presenting constructive insights into their perspectives. The main recommendations that emerge for practice are presented below and the researcher has placed same in order of importance based on the comments from the students:

$\checkmark \quad$ The most important change that is needed for this programme is in terms of alignment. This needs to be re-examined with a view to moving the delivery of the research methods module to just before the thesis module - semester 1, of the second year of the programme.

$\checkmark$ There is also some confusion still among the students in relation to what is needed and expected of them; therefore, an additional introductory class addressing this is needed, with an additional review mid-way through the process. This will have to be given outside of the main timetable, but the researcher is pleased to offer this to students during the month of January before the term commences as it is important.

$\checkmark$ Implement student note taking at the one-to-one meetings each week. This will prove beneficial for the student when reviewing work in private.

$\checkmark$ More structure is needed throughout the supervision. In fact, it is the author's view that less of a mentor approach should be used and more of a structured supervision. On reflection, I think that for this level, (taught), the mentor approach is too loose and that more "roadmaps" will need to be put in place to ease the stress of the students.

$\checkmark$ Devise and implement strict roadmaps for the students.

Timetable additional time management classes as reminders of how precious time is while conducting research. These will again have to be provided outside of the timetable proper, preferably at weekends when the adult learners are free. Two classes are proposed on two Saturdays at equal intervals. 
To improve the motivation of the students, it is recommended to organise a relevant student sage from industry to shadow the student and give the invaluable support and knowledge from practice that the supervisor could never provide.

$\checkmark \quad$ In terms of assessment, it is necessary to provide a strict rubric that the students can refer to from the outset and that will also limit any confusion in terms of what is required. Provide examples of past theses, to demonstrate the required standard.

These recommendations for practice should improve the overall experience for future students and feed into their highly motivated, demanding and keen interest in knowledge (Cross, 1981; Yap, 2009; Gegenfurtner, \& Vauras, 2012).

\section{Conclusion}

Recapturing the practice and 'mulling over it' is beneficial (Boud et al., 1985) and reflection is a form of mental processing that is used to fulfil a purpose around learning and thinking (Moon, 2001). It is important to examine aspects of our own practices that have been exposed through reflection in this module. A student centred approach to learning is required and the student must be supported. Reflection on the student surveys reveals that there were aspects of the supervision process that need to be addressed and reviewed for future delivery and the researcher was happy to have offered the students 'a voice' in this process for the first time. The relationship between learner and teacher is complex (Karmas, 2006), and this to be especially true in the context of the adult learner. The process has to work however, and the best and most applicable path taken for the students to fulfil their ambitions. They are also under extreme pressure due to the part-time nature of their study. The researcher recognises that the results were extremely positive and the student feedback was particularly encouraging, providing a solid platform from which to proceed, improve practice, and bring the supervision experience to a new level for both the student and supervisor.

In keeping with the findings of Moon, we have a lot of thoughts, feelings and ideas, but we just need to reflect on them and draw meaningful concepts from them. It is necessary to be more proactive and not complacent (Moon, 2001). The findings from this evaluation study will be

used to make improvements to the teaching and learning within the research thesis module and, by default, the research methodology module (Harvey,1998). It is, however, encouraging to see that the module is well received and appreciated in general terms by the students.

\section{References}

Armstrong, S. (2004). The Impact of Supervisor's Cognitive Styles on the Quality of Research Supervision. in Management Education. British Journal of Educational Psychology, 74, 599-616, http://dx.doi.org/10.1348/0007099042376436

Biggs, J. (1999). What the student does: teaching for enhanced learning. Higher Education Research and Development, 18(1), 57-75.

Biggs, J. (2003). Aligning teaching for constructing learning. The Higher Education Academy. 
Brew, A., \& Boud, D. (1995). Teaching and Research: Establishing the Vital Link with Learning. Springer, Higher Education, 29(3), 261-273.

Brown, S. (2007). Feedback and Feed-forward. The Higher Education Academy, Centre for Bioscience bulletin, 22, Autumn, ISSN 1740-6706 (Online).

Boud, D., Keogh, R., \& Walker, D. (1985). Promoting Reflection in Learning: A Model”. In D. Boud, R. Keogh, \& D. Walker (Eds), Reflection: Turning Experience into Learning. London: Kogan Page.

Cross, K.P. (1981). Adults as Learners. San Francisco: Jossey-Bass.

Cullen, S. (2009). Resource Guide to Dissertation Supervision on Taught Undergraduate and Postgraduate programmes The Hospitality, Leisure, Sport and Tourism Network, March, Thames Valley University.

Dewar, J. (2010). Faculty Development at LMU, July 2, 2010.

Donnelly , R., \& Fitzmaurice, M. (2005). Designing modules for learning Emerging issues in the practice of University Learning and Teaching, eds, Geraldine O'Neill, Sarah Moore and Barry McMullin, Dublin: AISHE, pp 99-110.

Enthwistle. N. (2009). Teaching for Understanding at University, Deep Approaches and Distinctive Ways of Thinking, US: Palgrgrave MacMillan.

Gatfield, T. (2005). Supervisory Styles: Overview \& Research available at http://researchsuper.chelt.anu.edu.au/being-supervisor/supervisory-styles/overview, accessed on December $6^{\text {th }}$ at $6 \mathrm{pm}$.

Gegenfurtner, A., \& Vauras, M. (2012). Age-related differences in the relation between motivation to learn and transfer of training in adult continuing education Contemporary Educational Psychology, 37(1), 33-46, ISSN 0361-476X.

Gibbs, G. (1998). The reflective Cycle. available at http://www.brookes.ac.uk/services/upgrade/a-z/reflective_gibbs.html, accessed on December $13^{\text {th }}$ at $11 \mathrm{pm}$.

Harvey, J. (1998). Evaluation Cookbook, Edinburgh: The Learning Technology Dissemination Initiative.

Harvey, J. (1998). Selecting your student sample in Evaluation Cookbook, ed., Jen Harvey, Scottish Higher Education Funding Council, Edinburg: The Learning Technology Dissemination Initiative.

Karmas, C. (2006). Active Learning in the Humanities Classroom, Everything, Nothing, Something, Anything. The international Journal of the Humanities, Active Learning in the Humanities Classroom, 3(6).

Lee, A. M. (2007). Developing effective supervisors: Concepts of research supervision South African Journal of Higher Education, SAJHE, 21(4). 
Lewis K. (2010). Pathways toward improving teaching and learning in higher education: International context and background. New Directions For Teaching \& Learning, 122, 13-23.

McAleese, M., Bladh, A., Berger, V., Bode, C., Muehlfeit, J., Petrin, T., Schiesaro, A., \& Tsoukalis, L. (2013). High Level Group on the Modernisation of Higher Education REPORT TO THE EUROPEAN COMMISSION ON Improving the quality of teaching and learning in Europe's higher education institutions, June.

Maslow, A. H. (1943). A Theory of Human Motivation. Psychological Review, 50, 370-396. http://dx.doi.org/10.1037/h0054346

MIT. Critical Moments Reflection Methodology, A Method for stepping back and draw lessons from the experience Center for Reflective Community Practice, available at http://www.kstoolkit.org/Critical+Moments, accessed on December 13 at $5 \mathrm{pm}$.

Milne, J. (1998). Quick Guide to Recipes in Evaluation Cookbook, ed., Jen Harvey, Scottish Higher Education Funding Council, Edinburg: The Learning Technology Dissemination Initiative.

Moon, J. (2001). PDP Working Paper 4, Reflection in Higher Education Learning LTSN Generic Centre, October, 5.

Oliver, M., \& Conole, G. (1998). Selecting A Methodology in Evaluation Cookbook, ed., Jen Harvey, Scottish Higher Education Funding Council, Edinburg: The Learning Technology Dissemination Initiative.

Penn State Commission for Adult Learners. (2012). Available at http://www.outreach.psu.edu/commission/, October, 31, accessed on December 5, at 10pm.

Race, P. (1993). Quality of assessment in Never Mind the Teaching Feel the Learning, SEDA Paper, 80.

Ramsden, P. (1992). Learning to Teach in Higher Education, NY: Routhledge Falmer. http://dx.doi.org/10.4324/9780203413937

Ramsden, P. (2003). Learning to Teach in Higher Education, $2^{\text {nd }}$ Ed, NY: Routhledge Falmer, ISBN-13: 978-0415303453 ISBN-10:

Rogers, C.R. (1969). Freedom to Learn. Columbus, OH: Merrill, available at http://www.instructionaldesign.org/theories/experiental-learning.html, accessed, December 2 at $7 \mathrm{pm}$.

Sorcinelli, M. (2007). Faculty Development: The Challenge Going Forward, 9(4).

Ullah, H., Khattak , Z.I., \& Siddiqa, I. (2011). The practice of constructive alignment based on personal experience model in higher education of Pakistan. Science Direct, Procedia Social and Behavioural Sciences, 15, 2391-2394. http://dx.doi.org/10.1016/j.sbspro.2011.04.114 


\section{Macrothink}

Journal of Studies in Education

ISSN 2162-6952 2016, Vol. 6, No. 1

Yap, Roger, \& Chao, R., JR. (2009). Understanding the Adult Learners Motivation and Barriers to Learning more ESREA, 6-8 November, University of Macedonia Thessaloniki Greece, available

http://www.academia.edu/1267765/Understanding_the_Adult_Learners_Motivation_and_Barriers_to_Learni ng, accessed on December 5, at 9pm.

Zhao, F. (2001). Postgraduate Research Supervision: A Process of Knowledge Management, RMIT University: Centre for Management Quality Research, Bundoora West, available at http://www.providersedge.com/docs/km_articles/Postgrad_Research_Supervision_-_A_Proce ss_of_KM.pdf, accessed December $10 @ 11 \mathrm{pm}$. 